\title{
Congenital diaphragmatic hernia
}

\author{
S. Kotecha*, A. Barbato ${ }^{\#}$, A. Bush ${ }^{\uparrow}$, F. Claus ${ }^{+}$, M. Davenport ${ }^{\S}$, C. Delacourt ${ }^{f}$, \\ J. Deprest**, E. Eber"\#\#, B. Frenckner ${ }^{\star \uparrow}$, A. Greenough ${ }^{++}$, A.G. Nicholson ${ }^{\S \S}$, \\ J.L. Antón-Pacheco ${ }^{f f}$ and F. Midulla***
}

ABSTRACT: Infants with congenital diaphragmatic hernia (CDH) have significant mortality and long-term morbidity. Only $\mathbf{6 0 - 7 0 \% ~ s u r v i v e ~ a n d ~ u s u a l l y ~ t h o s e ~ i n ~ h i g h - v o l u m e ~ c e n t r e s . ~ T h e ~ c u r r e n t ~}$ Task Force, therefore, has convened experts to evaluate the current literature and make recommendations on both the antenatal and post-natal management of $\mathrm{CDH}$. The incidence of CDH varies from 1.7 to 5.7 per $\mathbf{1 0 , 0 0 0}$ live-born infants depending on the study population. Antenatal ultrasound scanning is routine and increasingly complemented by the use of magnetic resonance imaging. For isolated $\mathrm{CDH}$, antenatal interventions should be considered, but the techniques need vigorous evaluation. After birth, management protocols are often used and have improved outcome in nonrandomised studies, but immediate intubation at birth and gentle ventilation are important. Pulmonary hypertension is common and its optimal management is crucial as its severity predicts the outcome. Usually, surgery is delayed to allow optimal medical stabilisation. The role of minimal invasive post-natal surgery remains to be further defined. There are differences in opinion about whether extracorporeal membrane oxygenation improves outcome. Survivors of $\mathrm{CDH}$ can have a high incidence of comorbidities; thus, multidisciplinary follow-up is recommended. Multicentre international trials are necessary to optimise the antenatal and post-natal management of $\mathrm{CDH}$ patients.

KEYWORDS: Antenatal ultrasound, congenital diaphragmatic hernia, congenital lung malformation

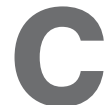
ongenital diaphragmatic hernia $(\mathrm{CDH})$ is an uncommon congenital malformation of the lung, but one with important implications for diagnosis, management and prognosis. It is associated with high mortality and although improvements in medical and surgical management have improved the outlook, survival remains at $60-70 \%$ [1-6]. Newer modalities, including antenatal screening and intervention, are available but are often introduced without formal evaluation. The current Task Force has convened experts in neonatal and paediatric respiratory medicine, paediatric pathology, fetal medicine, and paediatric surgery to evaluate the current literature and make recommendations for the management of $\mathrm{CDH}$.

\section{EPIDEMIOLOGY OF CDH}

To provide population-based incidence of congenital anomalies, the European Union's European Surveillance of Congenital Anomalies (EUROCAT) collects data from 43 European registries in 20 European countries, capturing $\sim 29 \%$ of Europe's birth population [7]. The reported incidence of $\mathrm{CDH}$ in 2008 for all pregnancies from 20 weeks onwards from EUROCAT was 2.62 per 10,000 [7] and 1.76 per 10,000 for live-born infants compared to $1.7-5.7$ per 10,000 reported by other studies [3, 8-10].

\section{PATHOLOGY OF CDH}

The diaphragm is complete by 8 weeks of gestation from its components including the septum transversum and the pleuroperitoneal membranes. In $\mathrm{CDH}$, the defect forms during the embryonic phase of lung development, usually on the left side $(85-90 \%)$, but can occur on the right or bilaterally and may be associated with other anomalies. The commonest (70\%) defect involves the posterolateral (Bochdalek) region of the diaphragm (fig. 1) but the anterior (Morgagni; $25-30 \%)$ or central regions $(2-5 \%)$ can also be affected [11]. Airway generations and terminal bronchioles are markedly decreased, alveolar
AFFILIATIONS

${ }^{*}$ Dept of Child Health, School of Medicine, Cardiff University, Cardiff, 'Depts of Paediatrics,

${ }^{\S}$ Histopathology, Royal Brompton and Harefield NHS Foundation Trust and National Heart and Lung Division, Imperial College London,

${ }^{\S}$ Dept of Paediatric Surgery, King's College Hospital,

${ }^{++}$Neonatal Intensive Care Unit, King's College London School of Medicine, London, UK,

\# Dept of Paediatrics, University of Padova, Padua,

***Paediatric Dept, Sapienza University of Rome, Rome, Italy, +Depts of Radiology,

**Obstetrics and Gynaecology, University Hospitals Leuven, Leuven, Belgium,

${ }^{f}$ Service de Pneumologie Pédiatrique, Hôpital Necker, Université Paris Descartes, Paris, France,

\#\# Dept of Paediatrics, University Children's Hospital, Medical University of Graz, Graz, Austria, " Dept of Paediatric Surgery, Astrid Lindgren Children's Hospital, Karolinska Institutet, Stockholm, Sweden, and

${ }^{f f}$ Division of Paediatric Surgery, Hospital U. 12 de Octubre, Universidad Complutense, Madrid, Spain.

\section{CORRESPONDENCE}

S. Kotecha, Dept of Child Health, Cardiff University School of Medicine, Heath Park, Cardiff CF14 4XN, UK E-mail: kotechas@cardiff.ac.uk

Received:

April 192011

Accepted after revision:

Aug 252011

First published online:

Oct 272011 
septa are thickened, and there is decreased complexity of the respiratory acinus and alveolar volume [12-15]. Arterial medial wall thickness is increased and peripheral muscularisation of smaller pre-acinar arteries occurs [12,16,17]. Overall, the lungs are hypoplastic, with lower than normal DNA and protein content, more so in the ipsilateral than contralateral lung [18].
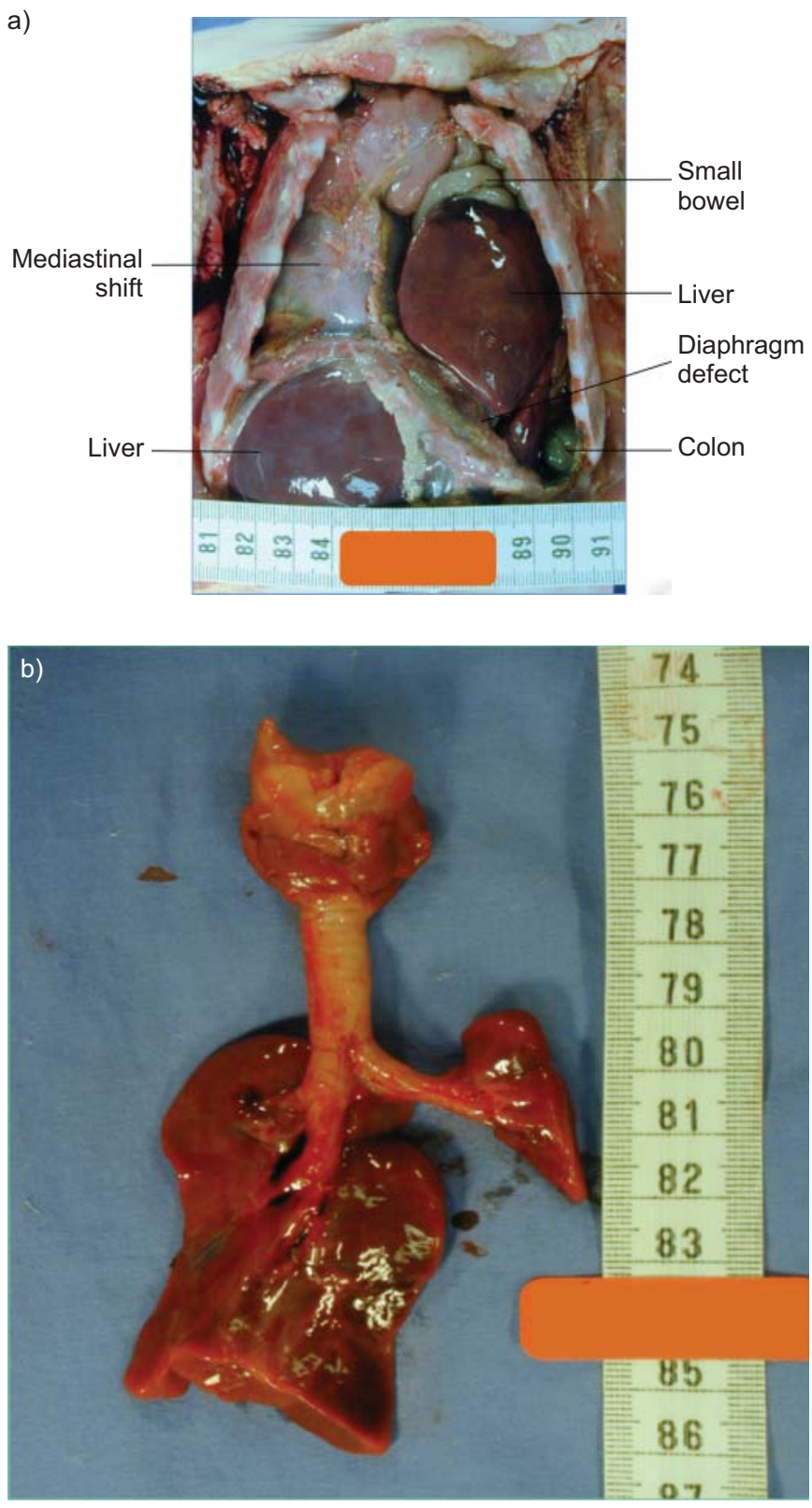

FIGURE 1. a) Only $\sim 0.5 \mathrm{~cm}$ of residual diaphragm can be observed, resulting in half of the liver, all of the small bowel, the stomach, spleen and pancreas, a large part of colon, the left adrenal gland, and approximately one-third of the left kidney herniating into the left thoracic cavity. The spleen is in the right chest behind the oesophagus but in front of the aorta. b) A lung weighing $13.43 \mathrm{~g}$ compared with a mean \pm SD expected weight of $40.6 \pm 17.1 \mathrm{~g}$. The lung/body ratio was 0.0045 (expected $>0.01$ ). Image kindly provided by E. Pollina (King's College Hospital, London, UK).

\section{IMAGING MODALITIES FOR CDH}

Antenatal ultrasound scanning for anomalies is routine in most industrialised countries and increasingly identifies congenital anomalies such as CDHs. Magnetic resonance imaging (MRI) is also increasingly used and should be seen to complement ultrasound scanning. Both these imaging modalities are discussed in detail in the online supplementary material. Our recommendations for antenatal management for delivery are summarised in table 1.

Antenatal presentation and imaging characteristics of $\mathrm{CDH}$ Antenatal ultrasound screening identifies $>70 \%$ of cases of $\mathrm{CDH}[19,20]$. Intrathoracic abdominal organs are the hallmark of $\mathrm{CDH}$ (fig. 2). Left-sided $\mathrm{CDH}$ typically presents with a mediastinal shift to the right, caused by herniation of the stomach and intestines. The viscera may show peristalsis and contrast with the more echogenic fetal lung. In right-sided $\mathrm{CDH}$, part of the liver is visible in the chest. Because the liver is echogenic, it may be difficult to differentiate from the lung. Doppler studies of the umbilical vein and hepatic vessels or location of the gall bladder may be used as additional landmarks. MRI is useful to confirm the diagnosis of $\mathrm{CDH}$ in cases of equivocal sonographic findings, to characterise the content of the herniated tissues [21]. Diaphragmatic eventration, characterised by defective diaphragmatic muscularisation, can be challenging to differentiate from $\mathrm{CDH}$ antenatally. The former shows a cephalic displacement of the diaphragm and is often associated with pleural and/or pericardial effusion [22]. Pathologies associated with $\mathrm{CDH}$ include cardiac, renal, central nervous system and gastrointestinal anomalies [23]. Amniocentesis and genetic consultation to screen for chromosomal anomalies are advised [24].

\section{Antenatal management and prognosis of $\mathrm{CDH}$}

Ultrasonographic lung size assessment is best undertaken by the use of the observed/expected lung-to-head ratio (LHR; discussed in the online supplementary material) [25]. The LHR predicts survival, with a trend for better prediction at 3233 weeks rather than 22-23 weeks, and short-term morbidity [26]. Right-sided lesions have worse outcome [27]. Threedimensional ultrasound and MRI both permit absolute volumetry, but MRI is superior mostly because of better visualisation of the ipsilateral lung [28]. MRI can quantify the extent of liver occupying the thorax $[29,30]$. Herniation of the liver is also related to survival, but it remains a matter of debate whether this is an independent predictor [26, 30, 31]. Efforts have been made to document antenatal lung vascular development, but the predictive value is still being validated. Measurements of the number of branches, vessel diameters, flow velocity or volume, and reactivity to maternal oxygen inhalation have been reported [32].

In all cases, delivery should be planned at a tertiary perinatal centre; in those with a poor prognosis (e.g. having other congenital abnormalities), termination of pregnancy may be considered. For isolated $\mathrm{CDH}$, antenatal therapy is an option. In utero anatomical repair improves lung development, but requires open fetal surgery and is not currently offered if there is liver herniation [33]. Alternatively, tracheal occlusion (TO) has been used to promote lung growth [34, 35]. Antenatal TO prevents egress of lung fluid, which increases airway pressure, 
TABLE 1 Recommendations for the antenatal management and delivery of congenital diaphragmatic hernia (CDH) infants

Routine antenatal ultrasound scanning for anomalies is essential in industrialised countries

$\mathrm{MRI}$ is useful to confirm the diagnosis of $\mathrm{CDH}$ in cases of equivocal ultrasound findings

Ultrasound lung size assessment is best determined by the use of the observed/expected LHR, which can be used to predict survival

Herniation of the liver is related to survival, although it is debatable whether it is an independent predictor of survival and, at this stage, should not be used to inform

counselling

Antenatal counselling is essential and should be conducted by a multidisciplinary team

Genetic consultation and amniocentesis to screen for chromosomal anomalies are advised

In those with a poor prognosis, e.g. fetuses having other congenital abnormalities, termination of pregnancy should be sensitively considered

Antenatal surgical intervention should be considered in selected cases after discussion with the parents, but going forward, this should be done in the context of

randomised trials

Delivery should be planned, wherever possible, in a tertiary perinatal centre

Obstetric decisions should guide the mode of delivery

MRI: magnetic resonance imaging; LHR: lung-to-head ratio.

causing cell proliferation, increased alveolar airspace and maturation of pulmonary vasculature. Sustained $\mathrm{TO}$ is deleterious, as it reduces type II cell numbers and surfactant expression. This can be alleviated by in utero release, a concept known as the "plug-unplug sequence" [36]. TO is possible by percutaneous fetoscopic endoluminal TO (FETO) via a 3.3-mm cannula without general anaesthesia [37]. The FETO consortium has the greatest experience in TO $(n=210)$ [27]. When compared with the predicted survival rate after expectant management, temporary FETO in fetuses with left CDH increased survival from $24 \%$ to $49 \%$ (left-sided) and from $0 \%$ to $35 \%$ (right-sided) (both $\mathrm{p}<0.001$ ) [27]. The procedure may cause premature rupture of membranes (17\% within 3 weeks). Changes in lung volume within 2 and 7 days after FETO may be predictive of subsequent survival but the technique is currently being evaluated in a randomised trial.
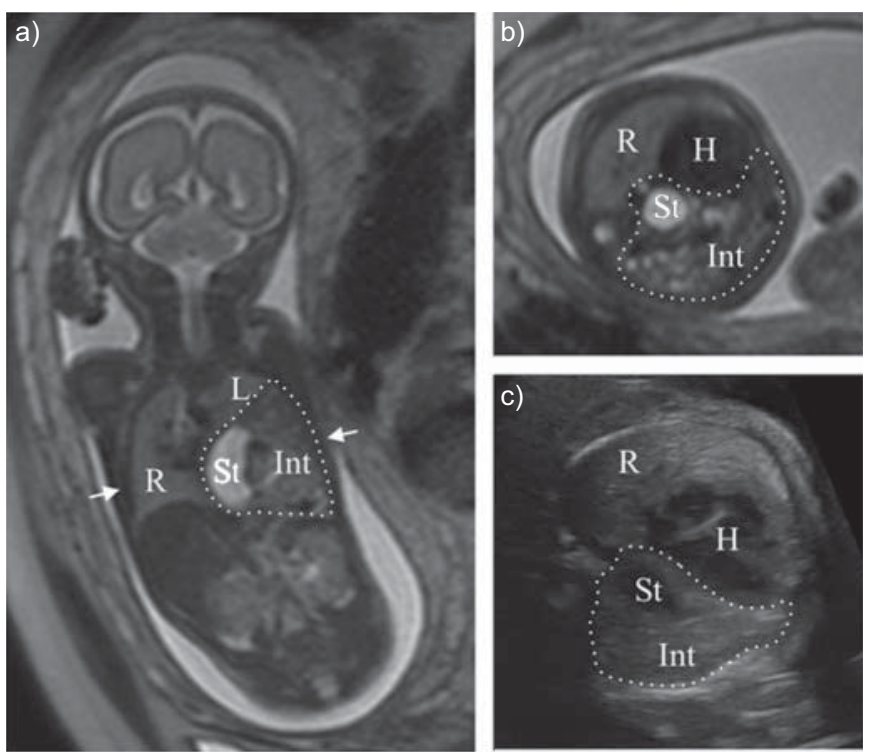

FIGURE 2. a) Coronal and b) axial fetal magnetic resonance images, and c) axial antenatal ultrasound of a left-sided congenital diaphragmatic hernia at gestational age 26 weeks. The level of both axial views is shown on the coronal image (arrows). The herniated tissue is outlined on the images (…). L: left lung; R: right lung; St: stomach; Int: intestines; $\mathrm{H}$ : heart.

\section{CLINICAL PRESENTATION OF CDH}

Clinical presentation of $\mathrm{CDH}$ is discussed in detail elsewhere $[10,38]$. Although increasing numbers of affected infants have planned deliveries after diagnosis by antenatal scanning, undiagnosed infants usually present with acute respiratory distress in the neonatal period. Milder forms may present with later mild respiratory or gastrointestinal symptoms. Sudden onset of respiratory distress may occur later in life due to small defects.

\section{INVESTIGATIONS FOR CDH}

A chest radiograph should be performed. In infants with $\mathrm{CDH}$, this will demonstrate an opacified hemithorax with a contralateral shift of the mediastinum. Bowel gas may be seen in the chest. The oesophageal portion of the nasogastric tube is deviated to the right in infants with left-sided $\mathrm{CDH}$ and to the left if the lesion is on the right [39]. Introduction of a radioopaque contrast medium into the stomach and proximal gastrointestinal tract can help to distinguish between a $\mathrm{CDH}$ and a congenital thoracic malformation such as congenital cystic adenomatoid malformation.

Echocardiography should be undertaken to exclude congenital cardiac lesions in infants with $\mathrm{CDH}$ and in any infant in whom pulmonary hypertension is suspected. It is important to determine right ventricular function, as the ability of the right ventricle to function under increased afterload is an important determinant of illness severity [40].

\section{POST-NATAL MANAGEMENT OF CDH Venue and timing of delivery}

Infants with $\mathrm{CDH}$ should be delivered in the hospital at which they will undergo surgical intervention. Analysis of the outcomes of 2,140 infants demonstrated infants transported for repair had a higher mortality and need for extracorporeal membrane oxygenation (ECMO) [41]. Analysis of data from 628 term infants from the $\mathrm{CDH}$ Study Group registry demonstrated early-term delivery by elective Caesarean section (37-38 versus 39-41 weeks) was associated with less use of ECMO and a trend towards greater survival later [42]. The CDH Study Group, however, found that the mode of delivery for 548 infants with $\mathrm{CDH}$ did not affect survival, although vaginal delivery was associated with higher use of ECMO [43], suggesting that obstetric decisions should guide mode of delivery. 


\section{Labour ward management}

Infants with $\mathrm{CDH}$ should be immediately intubated and ventilated, and peak inspiratory pressures $<25 \mathrm{cmH}_{2} \mathrm{O}$ employed. Face-mask and T-piece or bag and mask resuscitation should not be used, as this can cause distension of the herniated bowel, increasing respiratory embarrassment. A large-bore nasogastric tube (e.g. French gauge 8) should be sited to decompress the stomach and small bowel. Some advocate use of neuromuscular blocking agents to prevent swallowing and further gas distending the bowel.

\section{MANAGEMENT IN THE NEONATAL UNIT}

Standardised protocols have recently been published [44, 45] for the post-natal management of $\mathrm{CDH}$ with most recommending gentle ventilation and aggressive treatment of pulmonary hypertension. Both TRACY et al. [45] and VAN DEN HOUT et al. [1] have claimed improvements after introduction of standardised protocols, but their comparisons were with historical controls; thus, it is unclear whether the improvements are due to the introduction of the protocols or advances in medical care. Nevertheless, standardised protocols do ensure focus on essential aspects of management of $\mathrm{CDH}$; thus, we have based our recommendations on a consensus statement (table 2) [44]. It is important to emphasise that there have been few randomised trials evaluating the management of infants with $\mathrm{CDH}$ and multicentre international trials are urgently required to optimise the post-natal management of $\mathrm{CDH}$ infants.

\section{Respiratory support}

The best outcomes for $\mathrm{CDH}$ infants are achieved by early medical stabilisation and delay of surgical repair until optimisation has occurred [46]. Gentle ventilation, i.e. avoidance of high pressures (peak pressure $<25 \mathrm{cmH}_{2} \mathrm{O}$ and peak end-expiratory pressure $<5 \mathrm{cmH}_{2} \mathrm{O}$ [47]) and accepting higher levels of arterial carbon dioxide tension $\left(\mathrm{Pa}_{1} \mathrm{CO}_{2}\right)$ (permissive hypercapnia up to a $\mathrm{Pa}_{1} \mathrm{CO}_{2}$ of $60-65 \mathrm{mmHg}$ [48]), is preferred [49]. More than $90 \%$ of the International CDH Registry centres aimed to minimise lung injury by limiting the peak airway pressure and allowing permissive hypercapnia, rather than aiming for a low $\mathrm{Pa}_{\mathrm{a}} \mathrm{CO}_{2}$ to reduce pulmonary vascular resistance [50]. Some centres routinely use neuromuscular blocking agents, whereas others avoid them [51], as muscle paralysis may have an adverse effect on ventilation [49]. Indications for alternative forms of support (high-frequency oscillation ventilation (HFOV), inhaled nitric oxide (iNO) and ECMO) are a $\mathrm{pH}$ of $<7.25, \mathrm{~Pa}_{\mathrm{a}} \mathrm{CO}_{2}>60 \mathrm{mmHg}$ and preductal oxygen saturation less than $80-85 \%$ with an inspired oxygen concentration of $60 \%$ [52]. There is an ongoing multicentre randomised study (CDH-EURO Consortium) assessing whether elective HFOV improves survival and/or has other benefits (www.vicitrial.com); the results will be very welcome to inform the choice of respiratory support.

Analysis of data from 6,147 neonates from the Extracorporeal Life Support Organisation database (1991-2010) demonstrated an overall mortality rate of $49 \%$ for $\mathrm{CDH}$ infants supported by ECMO [53]. The short-term outcomes of veno-arterial and venovenous ECMO were similar [53]. In a UK collaborative ECMO trial, there were no significant differences in survival, but only a small number of patients were recruited [54]. Meta-analysis of three randomised controlled trials (RCTs) (only 39 infants in total) indicated a reduction in early mortality with ECMO, but no long-term benefits [55]. Prediction scores may be useful to identify those at very high risk of mortality amongst infants managed with ECMO [56]. Survival appears higher if surgical repair is after ECMO, rather than when the infant is on ECMO

TABLE 2 Post-natal recommendations for the management of congenital diaphragmatic hernia $(\mathrm{CDH})$ based on the consensus statement of the CDH-EURO consortium [44]

\begin{tabular}{|c|c|}
\hline \multirow[t]{2}{*}{ Treatment in the delivery room } & No resuscitation delivered by bag and mask \\
\hline & Nasogastric tube \\
\hline \multirow{3}{*}{ Treatment in the NICU } & $\mathrm{pH}>7.20$, lactate $3-5 \mathrm{mmol} \cdot \mathrm{L}^{-1}$ \\
\hline & $\mathrm{CMV}$ or $\mathrm{HFOV}$, maximum $\mathrm{PI}, \max 25-28 \mathrm{cmH}_{2} \mathrm{O}$ in $\mathrm{CMV}$ and $\bar{P}_{\text {aw }} 17 \mathrm{cmH}_{2} \mathrm{O}$ in $\mathrm{HFOV}$ \\
\hline & Targeting blood pressure: normal value for gestational age \\
\hline \multirow{3}{*}{ Pulmonary hypertension } & iNO but stop if no response \\
\hline & In the chronic phase: phosphodiesterase inhibitors, endothelin antagonists, tyrosine kinase \\
\hline & inhibitors \\
\hline \multirow[t]{2}{*}{ ECMO indications } & Inability to maintain preductal saturation $>85 \%$ \\
\hline & Respiratory acidosis \\
\hline Timing of surgical repair & No signs of $\mathrm{PH}$ \\
\hline
\end{tabular}

PI,max: peak inspiratory pressure; NICU: neonatal intensive care unit; CMV: conventional mechanical ventilation; HFOV: high-frequency oscillation ventilation; $\bar{P}$ aw: mean airway pressure; iNO: inhaled nitric oxide; ECMO: extracorporeal membrane oxygenation; $\mathrm{Fl}, \mathrm{O}_{2}$ : inspiratory oxygen fraction; $\mathrm{PH}$ : pulmonary hypertension. 
[57]. Opinions differ as to whether ECMO has superior outcomes than established optimal medical management.

There is debate over whether $\mathrm{CDH}$ infants have evidence of surfactant insufficiency [58]. Analysis of data from the CDH Study Group failed to highlight any significant benefits of surfactant administration in $>500$ neonates [59].

\section{Blood pressure support}

Arterial blood pressure levels should be maintained at levels that are normal for the patient's gestational age, but if there is evidence of pulmonary hypertension, the arterial blood pressure in term-born infants should be maintained at higher levels (i.e. $\geqslant 50 \mathrm{mmHg}$ ). Echocardiography should be undertaken to determine whether volume expansion is appropriate. There are no RCTs to determine which inotropes are the most effective in infants with $\mathrm{CDH}$.

\section{Treatment of pulmonary hypertension}

Pulmonary hypertension is common in infants with $\mathrm{CDH}$ [60]. The severity of pulmonary hypertension predicts the outcome, nonsurvivors in one series [60] having persistent systemic or suprasystemic pressures unresponsive to therapy for $>3$ weeks after birth. iNO improves oxygenation in up to $50 \%$ of cases [52], but the effect may be transitory and use of iNO does not influence overall outcome. No effect on mortality was seen with iNO administration in two randomised studies (rate ratio (RR) $1.20,95 \%$ CI $0.74-1.96)[61,62]$ and there was a slight increase in the requirement of ECMO (RR 1.27, 95\% CI 1.00-1.92) [63]. Sildenafil, a phosphodiesterase type 5 inhibitor, has been used to improve oxygenation and cardiac output by reducing pulmonary hypertension refractory to iNO $[64,65]$. It may also prevent rebound pulmonary hypertension during weaning of iNO [66]. There are only case reports of other therapies, such as endothelin antagonists and tyrosine kinase inhibitors, for pulmonary hypertension [49], and these clearly need further evaluation.

\section{SURGICAL MANAGEMENT OF CDH}

Surgical closure of the diaphragmatic defect is generally an uncomplicated procedure. Nevertheless there are some issues that are controversial. These include the timing of surgery, the nature of the repair (prosthetic patch versus primary repair), the need for abdominal closure and the merits of a minimally invasive approach.

\section{Timing of surgery}

The only two prospective randomised trials and one systematic review of early or delayed closure have failed to show a statistically significant difference in mortality and secondary variables (such as length of hospital stay, need for ECMO and duration of respiratory support) [67-69].

There are no universal criteria to define pre-operative stabilisation and this can occur with minimal delay in some patients, yet extend to many days in others [70]. While scientific evidence is lacking, it seems reasonable to delay surgery until medical stability has been achieved. Most surgeons now follow this protocol, as shown by the survey of 461 infants from the CDH Study Group [71]. More recent data have confirmed this trend (table 3) [72].

\begin{tabular}{lcc} 
TABLE 3 & $\begin{array}{l}\text { Number of patients whose diaphragmatic defect } \\
\text { was repaired within different time intervals after } \\
\text { birth }\end{array}$ & Patients $\mathbf{~}$ \\
& \\
& 185 \\
\hline $\mathbf{0 - 2 4}$ h & 376 \\
$\mathbf{2 4 - 4 8} \mathbf{~}$ & 2607 \\
$\mathbf{7 4 8} \mathbf{h}$ & 685 \\
No repair & 10 \\
Incomplete data & 3863 \\
Total & \\
\hline &
\end{tabular}

No consensus exists on when patients being stabilised on ECMO should be operated on. Some centres prefer to decannulate the patient before surgical repair, while others prefer to repair the diaphragm early or late in the ECMO course.

\section{Surgical technique}

The standard surgical approach to repair the diaphragmatic defect consists of a subcostal incision with removal of the herniated abdominal viscera from the thorax and complete exposure of the defect. A true hernia sac is sometimes observed $(<20 \%$ of cases) and, if present, should be excised. Closure of the defect can be accomplished primarily using nonabsorbable sutures or by means of a prosthetic patch (e.g. GORE-TEX ${ }_{\mathbb{R}}$ (W.L. Gore \& Associates, Newark, DE, USA), Marlex® (Phillips Petroleum Co., Bartlesville, OK, USA) or Permacol ${ }_{\circledR}$ (Covidien Surgical, Dublin, Ireland)) if the defect is large [70, 73]. Because synthetic material lacks the capacity for growth, hernia recurrence may reach up to $50 \%$ in some series [71]. Alternatively, muscle flaps have been used or a tissue-engineered diaphragm substitute has been proposed to close very large defects or even complete agenesis of the diaphragm [74, 75]. Little attention has been paid to the size of the prosthetic patch when performing a patch repair. A large, dome-shaped patch bulging into the thorax, compared with a small, flat patch, has the theoretical advantages of increasing the abdominal volume and decreasing the risk of patch dehiscence when the child grows. However, this question has not been evaluated scientifically. Up to half of those operated on for $\mathrm{CDH}$ will need a patch repair (table 4).

\begin{tabular}{lll} 
TABLE 4 & $\begin{array}{l}\text { Number of patients with primary versus patch } \\
\text { repair }\end{array}$ & Patients $\mathbf{n}$ \\
\hline Primary repair & 1562 \\
Patch repair & 1598 \\
No repair & 685 \\
Incomplete data & 18 \\
Total & 3863 \\
\hline
\end{tabular}

From January 1, 2000 to December 31, 2009, 3,863 patients were entered into the registry. 685 of these were never repaired. Data from [72] 
Closure of the abdominal wall may compromise ventilation and haemodynamic stability due to the small size of the abdominal cavity. In such circumstances, coverage of the abdominal viscera may be achieved by: skin closure, leaving a fascial defect; interposition of a prosthetic patch between the fascial edges; or creation of a surgical silo (table 5). A chest tube is not usually used, the rationale being to encourage the lung to enlarge gradually, displacing fluid and air, rather than forcefully due to a negative suction pressure applied through a thoracostomy drain $[73,76]$.

Neonates repaired on ECMO will almost invariably need a patch repair, as there is a strong correlation between the severity of the disease and the size of the defect [77]. These patients pose some specific problems related to bleeding. Careful inspection of the operative field and meticulous haemostasis should be performed at the end of the surgical procedure. Fibrin sealants or even the use $\varepsilon$-aminocaproic acid have been recommended in this setting [76]. However, in one of the author's (B. Frenckner) experience, the use of $\varepsilon$ aminocaproic acid has led to serious clotting in the ECMO circuit in several instances. Successful repair without bleeding complications was instead achieved in 34 out of the 36 infants recently repaired on ECMO by meticulous surgical haemostasis in combination with fibrin glue in the operating field (unpublished data).

Surgical repair can be accomplished by minimally invasive techniques, although the latent cardiopulmonary instability of such neonates has made some surgeons hesitate in using this approach. Certainly, hypercarbia and acidosis are almost invariable using carbon dioxide insufflation. Nevertheless, recent reports have shown the feasibility and safety of this approach even in unselected groups of patients [78-80]. It also seems that, in contrast to the open technique, where the abdominal approach is standard, thoracoscopic repair is somewhat easier. The role of minimally invasive surgery remains to be further defined and formally evaluated.

\section{LONG-TERM PROGNOSIS OF CDH Infancy}

Lung and vascular developmental abnormalities associated with $\mathrm{CDH}$ are the primary causes of morbidity and mortality in infants, which may be compounded by the secondary effects of post-natal management including hyperoxic, high-pressure mechanical ventilation. Prematurity is associated with worse

\begin{tabular}{ll}
\hline TABLE 5 & $\begin{array}{l}\text { Number of patients with primary closure of the } \\
\text { abdominal wall versus some type of secondary } \\
\text { closure }\end{array}$ \\
& Patients $\mathbf{n}$ \\
\hline Primary closure & 2595 \\
Silo, patch, etc. & 371 \\
No repair & 685 \\
Incomplete data & 212 \\
Total & 3863 \\
\hline
\end{tabular}

From January 1, 2000 to December 31, 2009, 3,863 patients were entered into the registry. 685 of these were never repaired. Data from [72] prognosis [81]. Lung hypoplasia, due to impairment of both airway branching and alveolarisation, results in markedly decreased alveolar surface area [82].

Significant advances in the post-natal management of patients with $\mathrm{CDH}$ have resulted in improved survival rates over the past two decades [46]. Nevertheless, most series still reported overall post-natal survival in isolated $\mathrm{CDH}$ around $60-70 \%$, although some survival rates of $>90 \%$ have recently been reported [83, 84]. A significant survival advantage has been suggested for infants with $\mathrm{CDH}$ treated in high-volume centres [85]. However, survival estimates derived from institutional or unit-based data lend themselves to multiple biases. A recent careful evaluation of survival variables comparing all institution and population data from the province of Ontario, Canada, demonstrated a clear discrepancy in institution-based reporting [86, 87]. The number of deaths reported by the institutions was found to be $32 \%$ less than that of the population data.

Late-presenting CDHs represent $<3 \%$ of cases [88]. Diagnosis may be at school age, with respiratory or gastrointestinal presenting symptoms. The prognosis is excellent.

The American Academy of Pediatrics has suggested follow-up guidelines for survivors of $\mathrm{CDH}$ after discharge [89]. These patients have a high incidence of respiratory, nutritional, musculoskeletal, neurological and gastrointestinal morbidities [46, 90-92]. Furthermore, the recent improved survival of very sick babies is associated with increased, particularly pulmonary, morbidity among survivors $[2,46]$ persisting beyond the initial hospitalisation, especially in those treated with ECMO $[93,94]$. SPOEL et al. [95] recently observed that mean maximal expiratory flows at functional residual capacity (FRC) were significantly lower than predicted values at 6 and 12 months of age in $\mathrm{CDH}$ survivors. Furthermore, FRC measured by plethysmography was increased especially in those patients who had received ECMO. Oxygen dependency is also common, with $50 \%$ being oxygen dependent at 28 days of age [1] and $16 \%$ requiring oxygen at the time of discharge for a mean duration of 14.5 months [93]. Up to $2 \%$ remained oxygen dependent at 2 yrs of age [94]. Bronchodilators may be needed in $40 \%$ of patients in the first year of life [93]. Angiogenesis remains defective in hypoplastic lungs [96]. Pulmonary hypertension may persist in up to $30 \%$ of patients at 2 months of age [97] and is associated with increased risk for early death [94, 97]. Pulmonary artery hypoplasia or stenosis, and pulmonary vein stenosis or delayed venous return may contribute to persistent pulmonary hypertension [98].

\section{Childhood}

Several follow-up studies have explored long-term pulmonary morbidity (table 6). These studies report catch-up of lung volumes [99-101, 103-105]. In contrast, perfusion studies have demonstrated persistent perfusion defects in the ipsilateral lung [103-105]. Reduced airflows and poor response to bronchodilator inhalation [101, 102, 105, 106] suggest increases in lung volume occur by distension rather than by alveolar number. The few lung morphometric studies following $\mathrm{CDH}$ repair [107, 108] all found persistent decreases in airway, alveolar and arterial numbers in both lungs, the ipsilateral lung being most affected. Nevertheless, studies evaluating the 


\begin{tabular}{|c|c|c|c|}
\hline TABLE 6 & \multicolumn{3}{|c|}{$\begin{array}{l}\text { Long-term outcomes of congenital } \\
\text { diaphragmatic hernia }\end{array}$} \\
\hline Feature & & Outcome & [Ref.] \\
\hline \multicolumn{2}{|c|}{ Thoracic scoliosis } & $\sim 8 \%$ & [99] \\
\hline \multicolumn{2}{|c|}{ Pectus excavatum } & $4-21 \%$ & {$[99,100]$} \\
\hline \multicolumn{2}{|l|}{ Mean TLC } & $89-101 \%$ pred & {$[99-101]$} \\
\hline \multicolumn{2}{|l|}{ Mean FEV 1} & $\begin{array}{l}\text { 0.16 Z-score } \\
79-90 \% \text { pred } \\
-1.45 \text { Z-score }\end{array}$ & $\begin{array}{c}{[102]} \\
{[99-101]} \\
{[102]}\end{array}$ \\
\hline \multicolumn{2}{|c|}{$\begin{array}{l}\text { Mean perfusion ratio of the affected } \\
\text { side }\end{array}$} & $53-67 \%$ & [103-105] \\
\hline \multicolumn{2}{|c|}{ Mean volume ratio of the affected side } & $82-88 \%$ & [103-105] \\
\hline \multicolumn{2}{|c|}{ Wheezing ever } & $17-37 \%$ & {$[100,101]$} \\
\hline \multicolumn{2}{|l|}{$V^{\prime} \mathrm{O}_{2}, \max$} & $95-100 \%$ control & {$[100,102]$} \\
\hline
\end{tabular}

diffusion capacity of the lung for carbon monoxide and exercise capacity have found normal values when compared with controls [100-102, 106].

Because $\mathrm{CDH}$ is associated with long-term morbidities that affect quality of life, survival alone is no longer a sufficient parameter for successful treatment of children with $\mathrm{CDH}$. Long-term follow-up by a multidisciplinary team is recommended for these children [89, 109], to detect and treat both pulmonary morbidities and other comorbidities.

\section{CONCLUSIONS}

$\mathrm{CDH}$ remains a challenging condition for optimal management and for optimal outcomes. Despite recent improvements in survival, the management, both ante- and post-natally, remains to be optimised, including the role of antenatal interventional management such as FETO. After birth, innovations have been made in treating both respiratory failure and pulmonary hypertension but robust assessment of newer therapies is necessary. As survival improves, further studies are required to ensure that the survivors have a high quality of life after discharge, which can only occur with regular followup by a multidisciplinary team.

\section{SUPPORT STATEMENT}

A. Bush and A.G. Nichdson were partly supported by the NIHR Respiratory Disease Biomedical Research Unit (Royal Brompton and Harefield NHS and Imperial College London, London, UK).

\section{STATEMENT OF INTEREST}

A statement of interest for A. Greenough can be found at www.erj. ersjournals.com/site/misc/statements.xhtml

\section{ACKNOWLEDGEMENTS}

We would like to thank E. Pollina (King's College Hospital, London, UK) for her contribution to the pathology section and for providing figure 1 .

\section{REFERENCES}

1 van den Hout L, Schaible T, Cohen-Overbeek TE, et al. Actual outcome in infants with congenital diaphragmatic hernia: the role of a standardized postnatal treatment protocol. Fetal Diagn Ther 2011; 29: 55-63.

2 van den Hout L, Reiss I, Felix JF, et al. Risk factors for chronic lung disease and mortality in newborns with congenital diaphragmatic hernia. Neonatology 2010; 98: 370-380.

3 Wright JC, Budd JL, Field DJ, et al. Epidemiology and outcome of congenital diaphragmatic hernia: a 9-year experience. Paediatr Perinat Epidemiol 2011; 25: 144-149.

4 Datin-Dorriere V, Rouzies $\mathrm{S}$, Taupin $\mathrm{P}$, et al. Prenatal prognosis in isolated congenital diaphragmatic hernia. Am J Obstet Gynecol 2008; 198: 80 e1-e5.

5 Sola JE, Bronson SN, Cheung MC, et al. Survival disparities in newborns with congenital diaphragmatic hernia: a national perspective. J Pediatr Surg 2010; 45: 1336-1342.

6 Seetharamaiah R, Younger JG, Bartlett RH, et al. Factors associated with survival in infants with congenital diaphragmatic hernia requiring extracorporeal membrane oxygenation: a report from the Congenital Diaphragmatic Hernia Study Group. J Pediatr Surg 2009; 44: 1315-1321.

7 EUROCAT: European Surveillance of Congenital Anomalies. www.eurocat-network.eu Date last accessed: January 14, 2011.

8 Langham MR Jr, Kays DW, Ledbetter DJ, et al. Congenital diaphragmatic hernia. Epidemiology and outcome. Clin Perinatol 1996; 23: 671-688.

9 Philip N, Gambarelli D, Guys JM, et al. Epidemiological study of congenital diaphragmatic defects with special reference to aetiology. Eur J Pediatr 1991; 150: 726-729.

10 Abel RM, Bush A, Chitty LS, et al. Congenital lung diseases. In: Chernick V, Boat TF, Wilmott RW, et al., eds. Kendig's Disorders of the Respiratory Tract. 7th Edn. Philadelphia, Elsevier Saunders, 2006; pp. 280-316.

11 Keijzer R, Puri P. Congenital diaphragmatic hernia. Semin Pediatr Sur 2010; 19: 180-185.

12 Areechon W, Reid L. Hypoplasia of lung with congenital diaphragmatic hernia. Br Med J 1963; 1: 230-233.

13 Kitagawa M, Hislop A, Boyden EA, et al. Lung hypoplasia in congenital diaphragmatic hernia. A quantitative study of airway, artery and alveolar development. Br J Surg 1971; 58: 342-346.

14 Askenazi SS, Perlman M. Pulmonary hypoplasia: lung weight and radial alveolar count as criteria of diagnosis. Arch Dis Child 1979; 54: 614-618.

15 Wigglesworth JS, Desai R, Guerrini P. Fetal lung hypoplasia: biochemical and structural variations and their possible significance. Arch Dis Child 1981; 56: 606-615.

16 Reid LM. The lung: its growth and remodeling in health and disease. Am J Roentgenol 1977; 129: 777-782.

17 Levin DL. Morphologic analysis of the pulmonary vascular bed in congenital left-sided diaphragmatic hernia. J Pediatr 1978; 92: 805-809.

18 Wigglesworth JS, Desai R. Use of DNA estimation for growth assessment in normal and hypoplastic fetal lungs. Arch Dis Child 1981; 56: 601-605.

19 Dillon E, Renwick M, Wright C. Congenital diaphragmatic herniation: antenatal detection and outcome. Br J Radiol 2000; 73: 360-365.

20 Garne E, Haeusler M, Barisic I, et al. 2002. Congenital diaphragmatic hernia: evaluation of prenatal diagnosis in 20 European regions. Ultrasound Obstet Gynecol 2002; 19: 329-333.

21 Claus F, Sandaite I, Dekoninck P, et al. Prenatal anatomical imaging in fetuses with congenital diaphragmatic hernia. Fetal Diagn Ther 2011; 29: 88-100.

22 Jeanty C, Nien JK, Espinoza J, et al. Pleural and pericardial effusion: a potential ultrasonographic marker for the prenatal differential diagnosis between congenital diaphragmatic eventration and congenital diaphragmatic hernia. Ultrasound Obstet Gynecol 2007; 29: 378-387. 
23 Graham G, Devine PC. Antenatal diagnosis of congenital diaphragmatic hernia. Sem Perinatol 2005; 29: 69-76.

24 Klaassens M, de Klein A, Tibboel D. The etiology of congenital diaphragmatic hernia: still largely unknown? Eur J Med Genet 2009; 52; 281-286.

25 Metkus AP, Filly RA, Stringer MD, et al. Sonographic predictors of survival in fetal diaphragmatic hernia. J Ped Surg 1996; 31: 148-152.

26 Jani JC, Nicolaides KH, Benachi A, et al. Timing of lung size assessment in the prediction of survival in fetuses with diaphragmatic hernia. Ultrasound Obstet Gynecol 2008; 31: 37-40.

27 Jani JC, Nicolaides KH, Gratacós E, et al. Severe diaphragmatic hernia treated by fetal endoscopic tracheal occlusion. Ultrasound Obstet Gynecol 2009; 34: 304-310.

28 Jani JC, Cannie M, Peralta CF, et al. Lung volumes in fetuses with congenital diaphragmatic hernia: comparison of 3D US and MR imaging assessments. Radiology 2007; 244: 575-582.

29 Walsh DS, Hubbard AM, Olutoye OO, et al. Assessment of fetal lung volumes and liver herniation with magnetic resonance imaging in congenital diaphragmatic hernia. Am J Obstet Gynecol 2000; 183: 1067-1069.

30 Cannie M, Jani J, Chaffiotte C, et al. Quantification of intrathoracic liver herniation by magnetic resonance imaging and prediction of postnatal survival in fetuses with congenital diaphragmatic hernia. Ultrasound Obstet Gynecol 2008; 32: 627-632.

31 Hedrick HL, Danzer E, Merchant A, et al. Liver position and lung-to-head ratio for prediction of extracorporeal membrane oxygenation and survival in isolated left congenital diaphragmatic hernia. Am J Obstet Gynecol 2007; 197: 422.e1-e4.

32 Gucciardo L, Deprest J, Done' E, et al. Prediction of outcome in isolated congenital diaphragmatic hernia and its consequences for fetal therapy. Best Pract Res Clin Obstet Gynaecol 2008; 22 123-138.

33 Harrison MR, Scott Adzick N, Flake AW, et al. Correction of congenital diaphragmatic hernia in utero: VI. Hard-earned lessons. J Pediatr Surg 1993; 28: 1411-1418.

34 Di Fiore JW, Fauza DO, Slavin R, et al. Experimental fetal tracheal ligation reverses the structural and physiological effects of pulmonary hypoplasia in congenital diaphragmatic hernia. J Pediatr Surg 1994; 29: 248-257.

35 Ruano R, Duarte SA, Pimenta EJ, et al. Comparison between fetal endoscopic tracheal occlusion using a 1.0-mm fetoscope and prenatal expectant management in severe congenital diaphragmatic hernia. Fetal Diagn Ther 2011; 29: 64-70.

36 Flageole H, Evrard VA, Piedboeuf B, et al. The plug-unplug sequence: an important step to achieve type II pneumocyte maturation in the fetal lamb model. J Pediatr Surg 1998; 33: 299-303.

37 Deprest J, Gratacos E, Nicolaides KH. Fetoscopic tracheal occlusion (FETO) for severe congenital diaphragmatic hernia: evolution of a technique and preliminary results. Ultrasound Obstet Gynecol 2004; 24: 121-126.

38 Chang SW, Lee HC, Yeung CY, et al. A twenty-year review of early and late-presenting congenital Bochdalek diaphragmatic hernia: are they different clinical spectra? Pediatr Neonatol 2010; 51: $26-30$.

39 Taylor GA, Atalabi OM, Estroff JA. Imaging of congenital diaphragmatic hernias. Pediatr Radiol 2009; 39: 1-16.

40 Patel N, Mills JF, Cheung MM. Use of the myocardial performance index to assess right ventricular function in infants with pulmonary hypertension. Pediatr Cardiol 2009; 30: 133-137.

41 Aly H, Bianco-Batlles D, Mohamed MA, et al. Mortality in infants with congenital diaphragmatic hernia: a study of the United States National Database. J Perinatol 2010; 30: 553-557.

42 Stevens TP, van Wijngaarden E, Ackerman KG, et al. Timing of delivery and survival rates for infants with prenatal diagnoses of congenital diaphragmatic hernia. Paediatrics 2009; 123: 494-502.
43 Frenckner BP, Lally PA, Hintz SR, et al. Prenatal diagnosis of congenital diaphragmatic hernia: how should the babies be delivered? J Pediatr Surg 2007; 42: 1533-1538.

44 Reiss I, Schaible T, van den Hout $\mathrm{L}$, et al. Standardized postnatal management of infants with congenital diaphragmatic hernia in Europe: the CDH EURO Consortium consensus. Neonatology 2010; 98: 354-364.

45 Tracy ET, Mears SE, Smith PB, et al. Protocolized approach to the management of congenital diaphragmatic hernia: benefits of reducing variability in care. J Ped Surg 2010; 45: 1343-1348.

46 Chiu P, Hedrick HL. Postnatal management and long term outcome for survivors with congenital diaphragmatic hernia. Prenat Diagn 2008; 28: 592-603.

47 Downard CD, Jaksic T, Garza JJ, et al. Analysis of an improved survival rate for congenital diaphragmatic hernia. J Pediatr Surg 2003; 8: 729-732.

48 Logan JW, Cotten CM, Goldberg RN, et al. Mechanical ventilation strategies in the management of congenital diaphragmatic hernia. Semin Pediatr Surg 2007; 16: 115-125.

49 van den Hout L, Sluiter I, Gischler S, et al. Can we improve outcome of congenital diaphragmatic hernia? Pediatr Surg Int 2009; 25: 733-743.

50 Logan JW, Rice HE, Goldberg RN, et al. Congenital diaphragmatic hernia: a systematic review and summary of best-evidence practice strategies. J Perinatol 2007; 27: 535-549.

51 Brown RA, Bosenberg AT. Evolving management of congenital diaphragmatic hernia. Paediatr Anaesth 2007; 17: 713-719.

52 Bosenberg AT, Brown RA. Management of congenital diaphragmatic hernia. Curr Opin Anaesthesiol 2008; 21: 323-331.

53 Guner YS, Khemani RG, Qureshi FG, et al. Outcome analysis of neonates with congenital diaphragmatic hernia treated with venovenous vs venoarterial extracorporeal membrane oxygenation. J Pediatr Surg 2009; 44: 1691-1701.

54 UK Collaborative ECMO Trial Group. UK collaborative randomised trial of neonatal extracorporeal membrane oxygenation. Lancet 1996; 348: 75-82.

55 Morini F, Goldman A, Pierro A. Extracorporeal membrane oxygenation in infants with congenital diaphragmatic hernia: a systematic review of the evidence. Eur J Pediatr Surg 2006; 16: 385-391.

56 Haricharan RN, Barnhart DC, Cheng $\mathrm{H}$, et al. Identifying neonates at a very high risk for mortality among children with congenital diaphragmatic hernia managed with extracorporeal membrane oxygenation. J Ped Surg 2009; 44: 87-93.

57 Congenital Diaphragmatic Hernia Study Group, Bryner BS, West $\mathrm{BT}$, et al. Congenital diaphragmatic hernia requiring extracorporeal membrane oxygenation: does timing of repair matter? J Pediatr Surg 2009; 44: 1165-1172.

58 Davey M. Surfactant levels in congenital diaphragmatic hernia PLoS Med 2007; 4: e243.

59 Colby CE, Lally KP, Hintz SR, et al. Surfactant replacement therapy on ECMO does not improve outcome in neonates with congenital diaphragmatic hernia. J Pediatr Surg 2004; 39: 1632-1637.

60 Mohseni-Bod H, Bohn D. Pulmonary hypertension in congenital diaphragmatic hernia. Semin Pediatr Surg 2007; 16: 126-133.

61 The Neonatal Inhaled Nitric Oxide Study Group (NINOS). Inhaled nitric oxide and hypoxic respiratory failure in infants with congenital diaphragmatic hernia. Paediatrics 1997; 99: 838-845.

62 Clark RH, Kueser TJ, Walker MW, et al. Low dose nitric oxide therapy for persistent pulmonary hypertension of the newborn. N Engl J Med 2000; 342: 469-474.

63 Finer NN, Barrington KJ. Nitric oxide for respiratory failure in infants born at or near term. Cochrane Database Sys Rev 2006; 18: CD000399. 
64 Noori S, Friedlich P, Wong P, et al. Cardiovascular effects of sildenafil in neonates and infants with congenital diaphragmatic hernia and pulmonary hypertension. Neonatology 2007; 91: 92-100.

65 De Luca D, Zecca E, Vento G, et al. Transient effect of epoprostenol and sildenafil combined with iNO for pulmonary hypertension in congenital diaphragmatic hernia. Pediatr Anaesth 2006; 16; 597-598.

66 Atz AM, Wessel DL. Sildenafil ameliorates effects of inhaled nitric oxide withdrawal. Anesthesiology 1999; 91: 307-310.

67 de la Hunt MN, Madden N, Scott JE, et al. Is delayed surgery really better for congenital diaphragmatic hernia? a prospective randomized clinical trial. J Pediatr Surg 1996; 31: 1554-1556.

68 Nio M, Haase G, Kennaugh J, et al. A prospective randomized trial of delayed versus immediate repair of congenital diaphragmatic hernia. J Pediatr Surg 1994; 29: 618-621.

69 Niramis R. Technology assessment for management of congenital diaphragmatic hernia: immediate versus delayed surgery. J Med Assoc Thai 2003; 86: Suppl. 3, S727-S733.

70 Harting MT, Lally KP. Surgical management of neonates with congenital diaphragmatic hernia. Sem Pediatr Surg 2007; 16: 109-114.

71 Clark RH, Hardin WD, Hirschl RB, et al. Current surgical management of congenital diaphragmatic hernia: a report from the Congenital Diaphragmatic Hernia Study Group. J Pediatr Surg 1998; 33: 1004-1009.

72 CDH Study Group. Report from the Congenital Diaphragmatic Hernia Study Group. http://utsurg.uth.tmc.edu/pedisurgery/ cdhsg/CDHSG.pdf Date last accessed: March 10, 2011. Date last updated: October 25, 2010.

73 Mitchell IC, Garcia NM, Barber R, et al. Permacol: a potential biologic patch alternative in congenital diaphragmatic hernia repair. J Pediatr Surg 2008; 43: 2161-2164.

74 Fuchs JR, Kaviani A, Oh JT, et al. Diaphragmatic reconstruction with autologous tendon engineered from mesenchymal amniocytes. J Pediatr Surg 2004; 39: 834-838.

75 Samarakkody U, Klaassen M, Nye B. Reconstruction of congenital agenesis of hemidiaphragm by combined reverse latissimus dorsi and serratus anterior muscle flaps. J Pediatr Surg 2001; 36: 1637-1640.

76 Wung JT, Sahni R, Moffitt ST, et al. Congenital diaphragmatic hernia: survival treated with very delayed surgery, spontaneous respiration, and no chest tube. J Pediatr Surg 1995; 30: 406-409.

77 Lally KP, Lally PA, Lasky RE, et al. Defect size determines survival in infants with congenital diaphragmatic hernia. Paediatrics 2007; 120: e651-e657.

78 Arca MJ, Barnhart DC, Lelli JL, et al. Early experience with minimally invasive repair of congenital diaphragmatic hernias: results and lessons learned. J Pediatr Surg 2003; 38: 1563-1568.

79 Cho SD, Krishnaswami S, Mckee JC, et al. Analysis of 29 consecutive thoracoscopic repairs of congenital diaphragmatic hernia in neonates compared to historical controls. J Pediatr Surg 2009; 44: 80-86.

80 Lao OB, Crouthamel MR, Goldin AB, et al. Thoracoscopic repair of congenital diaphragmatic hernia in infancy. J Laparoendosc Adv Surg Tech A 2010; 20: 271-276.

81 Tsao K, Allison ND, Harting MT, et al. Congenital diaphragmatic hernia in the preterm infant. Surgery 2010; 148: 404-410.

82 Boucherat $\mathrm{O}$, Benachi A, Storme L, et al. New insights in congenital diaphragmatic hernia. Curr Respir Med Rev 2008; 4: 157-173.

83 Betremieux P, Gaillot T, de la Pintiere A, et al. Congenital diaphragmatic hernia: prenatal diagnosis permits immediate intensive care with high survival rate in isolated cases. A population-based study. Prenat Diagn 2004; 24: 487-493.

84 Masumoto K, Teshiba R, Esumi G, et al. Improvement in the outcome of patients with antenatally diagnosed congenital diaphragmatic hernia using gentle ventilation and circulatory stabilization. Pediatr Surg Int 2009; 25: 487-492.

85 Grushka JR, Laberge JM, Puligandla P, et al. Effect of hospital case volume on outcome in congenital diaphragmatic hernia: the experience of the Canadian Paediatric Surgery Network. J Pediatr Surg 2009; 44: 873-876.

86 Mah VK, Zamakhshary M, Mah DY, et al. Absolute vs relative improvements in congenital diaphragmatic hernia survival: what happened to "hidden mortality". J Pediatr Surg 2009; 44: 877-882.

87 Mah VK, Chiu P, Kim PC. Are we making a real difference? Update on "hidden mortality" in the management of congenital diaphragmatic hernia. Fetal Diag Therapy 2011; 29: 40-45.

88 Kitano Y, Lally KP, Lally PA. Late-presenting congenital diaphragmatic hernia. J Pediatr Surg 2005; 40: 1839-1843.

89 American Academy of Pediatrics Section on Surgery, American Academy of Pediatrics Committee on Fetus and Newborn, Lally $\mathrm{KP}$, et al. Postdischarge follow-up of infants with congenital diaphragmatic hernia. Pediatrics 2008; 121: 627-632.

90 Peetsold MG, Heij HA, Kneepkens CM, et al. The long-term follow-up of patients with a congenital diaphragmatic hernia: a broad spectrum of morbidity. Pediatr Surg Int 2009; 25: 1-17.

91 Danzer E, Gerdes M, Bernbaum J, et al. Neurodevelopmental outcome of infants with congenital diaphragmatic hernia prospectively enrolled in an interdisciplinary follow-up program. J Pediatr Surg 2010; 45: 1759-1766.

92 van der Cammen-van Zijp MH, Gischler SJ, Mazer P, et al. Motor-function and exercise capacity in children with major anatomical congenital anomalies: an evaluation at 5 years of age. Early Hum Dev 2010; 86: 523-528.

93 Muratore CS, Kharasch V, Lund DP, et al. Pulmonary morbidity in 100 survivors of congenital diaphragmatic hernia monitored in a multidisciplinary clinic. J Pediatr Surg 2001; 36: 133-140.

94 Jaillard SM, Pierrat V, Dubois A, et al. Outcome at 2 years of infants with congenital diaphragmatic hernia: a populationbased study. Ann Thorac Surg 2003; 75: 250-256.

95 Spoel M, ven den Hout L, Gischler SJ, et al. Prospective longitudinal evaluation of lung function during the first year of life after repair of congenital diaphragmatic hernia. Paediatr Crit Care 2011; [Epub ahead of print DOI: 10.1097/PCC. 0b013e3182231872].

96 Boucherat O, Franco-Montoya ML, Delacourt C, et al. Defective angiogenesis in hypoplastic human fetal lungs correlates with nitric oxide synthase deficiency that occurs despite enhanced angiopoietin-2 and VEGF. Am J Physiol Lung Cell Mol Physiol 2010; 298: L849-L856.

97 Dillon PW, Cilley RE, Mauger D, et al. The relationship of pulmonary artery pressure and survival in congenital diaphragmatic hernia. J Pediatr Surg 2004; 39: 307-312.

98 Kinsella JP, Ivy DD, Abman SH. Pulmonary vasodilator therapy in congenital diaphragmatic hernia: acute, late, and chronic pulmonary hypertension. Semin Perinatol 2005; 29: 123-128.

99 Stefanutti G, Filippone M, Tommasoni N, et al. Cardiopulmonary anatomy and function in long-term survivors of mild to moderate congenital diaphragmatic hernia. J Pediatr Surg 2004; 39: 526-531.

100 Marven SS, Smith CM, Claxton D, et al. Pulmonary function, exercise performance, and growth in survivors of congenital diaphragmatic hernia. Arch Dis Child 1998; 78: 137-142.

101 Trachsel D, Selvadurai H, Bohn D, et al. Long-term pulmonary morbidity in survivors of congenital diaphragmatic hernia. Pediatr Pulmonol 2005; 39: 433-439.

102 Peetsold MG, Heij HA, Nagelkerke AF, et al. Pulmonary function and exercise capacity in survivors of congenital diaphragmatic hernia. Eur Respir J 2009; 34: 1140-1147.

103 Nagaya M, Akatsuka H, Kato J, et al. Development in lung function of the affected side after repair of congenital diaphragmatic hernia. J Pediatr Surg 1996; 31: 349-356. 
104 Kamata S, Usui N, Kamiyama M, et al. Long-term follow-up of patients with high-risk congenital diaphragmatic hernia. J Pediatr Surg 2005; 40: 1833-1838.

105 Falconer AR, Brown RA, Helms P, et al. Pulmonary sequelae in survivors of congenital diaphragmatic hernia. Thorax 1990; 45: 126-169.

106 Ijsselstijn H, Tibboel D, Hop WJ, et al. Long-term pulmonary sequelae in children with congenital diaphragmatic hernia. Am J Respir Crit Care Med 1997; 155: 174-180.
107 Hislop A, Reid L. Persistent hypoplasia of the lung after repair of congenital diaphragmatic hernia. Thorax 1976; 31: 450-455.

108 Thurlbeck WM, Kida K, Langston C, et al. Postnatal lung growth after repair of diaphragmatic hernia. Thorax 1979; 34: 338-343.

109 Gischler SJ, Mazer P, Duivenvoorden HJ, et al. Interdisciplinary structural follow-up of surgical newborns: a prospective evaluation. J Pediatr Surg 2009; 44: 1382-1389. 